\title{
BALANÇO DE MASSA DE REATORES ANAERÓBIOS DE FLUXO ASCENDENTE COM MANTA DE LODO (UASB) TRATANDO ÁGUAS RESIDUÁRIAS DE SUINOCULTURA ${ }^{1}$
}

\section{ROBERTO A. DE OLIVEIRA ${ }^{2}$, EUGÊNIO FORESTI ${ }^{3}$}

RESUMO: Foi obtido o balanço de massa, a partir dos valores médios das determinações de demanda química de oxigênio (DQO) e produção de metano $\left(\mathrm{CH}_{4}\right)$, em dois reatores UASB de bancada com volume de 10,5 L tratando águas residuárias de suinocultura, submetidos a condições operacionais distintas no que diz respeito às concentrações de sólidos suspensos totais do afluente (SST de 500; $1.000 ; 1.500$ e $2.000 \mathrm{mg} \mathrm{L}^{-1}$ ), tempo de detenção hidráulica (TDH de 30;20;12 e 8 h), taxas de carregamento orgânico volumétrico (TCOV de 0,8 a $8,0 \mathrm{~kg}$ DQO total $\left(\mathrm{m}^{3} \mathrm{~d}\right)^{-1}$ ) e temperatura (ambiente e controlada a $25^{\circ}$ e $30^{\circ} \mathrm{C}$ ). Verificou-se que a DQO total removida convertida $\mathrm{em}^{\mathrm{CH}_{4}}$ variou de 28 a $51 \%$ e a relação DQO- $\mathrm{CH}_{4}$ por DQO dissolvida removida de 0,94 a 2,07; indicando alta participação da remoção física dos sólidos do afluente, de 49 a $72 \%$, na remoção de DQO total nos reatores, a qual variou de 75 a 92\%. A concentração de SST do afluente, a temperatura, o TDH e a TCOV influenciaram nesse desempenho dos reatores UASB.

PALAVRAS-CHAVE: digestão anaeróbia, tratamento anaeróbio, resíduos de suinocultura.

\section{MASS BALANCE IN UPFLOW ANAEROBIC SLUDGE BED REACTORS (UASB) TREATING SWINE WASTEWATER}

SUMMARY: The mass balance was acquired out in order to determinate the mean values of chemical oxygen demand (COD) and methane $\left(\mathrm{CH}_{4}\right)$ production from two UASB reactors treating swine wastewater subjected to distinct operational conditions in respect to concentrations of total suspended solids of the affluent (TSS of 500; 1,000; 1,500 and 2,000 mg L $\mathrm{mg}^{-1}$ ), hydraulic detention time (HDT of $30 ; 20 ; 12$ and $8 \mathrm{~h}$ ), volumetric organic loading rates (VOLR of 0.8 to $8.0 \mathrm{~kg}$ COD $\left(\mathrm{m}^{3} \mathrm{~d}\right)^{-1}$ ) and temperature (ambient, $25{ }^{\circ} \mathrm{C}$ and $30{ }^{\circ} \mathrm{C}$ ). It was verified that values of total COD removed and converted in $\mathrm{CH}_{4}$ varied from 28 to $51 \%$ and the ratio values of $\mathrm{COD}-\mathrm{CH}_{4}$ by removed and dissolved COD varied from 0.94 to 2.07; indicating a high participation of physical removal (49 to $72 \%$ ) of the affluent solids in the process. The TSS concentrations, temperature, HDT and VOLR influenced the UASB reactors performance.

KEYWORDS: anaerobic digestion, anaerobic treatment, swine waste.

\section{INTRODUÇÃO}

Do ponto de vista da necessidade de implementação de tecnologias sustentáveis, os processos anaeróbios podem resolver os problemas de resíduos de forma mais holística (LETTINGA, 1996), visto que: é produzida energia aproveitável na forma de metano; pequena porcentagem da demanda química de oxigênio é convertida em biomassa nova; com os modernos sistemas de tratamento anaeróbio, os espaços necessários são pequenos; podem ser alternativas de baixo custo porque os

\footnotetext{
${ }^{1}$ Parte de Projeto Temático financiado pela FAPESP.

${ }^{2}$ Eng $^{\mathrm{o}}$ Agrônomo e Tecnólogo em Construção Civil, Prof. Dr., Faculdade de Ciências Agrárias Agrárias e Veterinárias - FCAV/UNESP, Câmpus de Jaboticabal, Depto. de Engenharia Rural, Via de Acesso Prof. Paulo Donato Castellane, km 5, Jaboticabal - SP, Fone: (0XX16) 3209.2637, Fax: (0XX16) 3202.4275, e-mail: oliveira@ fcav.unesp.br.

${ }^{3}$ Eng ${ }^{0}$ Civil, Prof. Titular, Escola de Engenharia de São Carlos, EESC/USP, Câmpus de São Carlos - SP.

Recebido pelo Conselho Editorial em: 6-9-2001

Aprovado pelo Conselho Editorial em: 5-11-2004
} 
reatores são tecnologicamente simples e podem propiciar a recuperação de produtos associados a amônia, enxofre e fósforo.

O desenvolvimento do reator anaeróbio de fluxo ascendente com manta de lodo (UASB) (LETTINGA et al., 1980) combinou vantagens, as quais possibilitaram a sua utilização para uma grande variedade de águas residuárias e, conseqüentemente, adoção em larga escala. Contudo, como outras configurações de reatores anaeróbios, o reator UASB também está sujeito a limitações relacionadas à concentração de sólidos suspensos totais (SST) do afluente, o que tem prejudicado a sua indicação para tratamento de águas residuárias agropecuárias, como as de suinocultura. LETTINGA et al. (1980) recomendaram valores de SST do afluente menores que $1.000 \mathrm{mg} \mathrm{L}^{-1}$. STRONACH et al. (1986) indicaram valores menores que $500 \mathrm{mg} \mathrm{L}^{-1}$, ao passo que SOUZA (1986) recomendou SST menor que $1.000 \mathrm{mg} \mathrm{L}^{-1}$ e a relação SST/DQO menor que 0,5. LETTINGA \& HULSHOFF-POL (1991) apresentaram recomendações de 6.000 a $8.000 \mathrm{mg} \mathrm{L}^{-1}$ de SST no afluente.

Os resíduos de suinocultura causam problemas de poluição e contaminação das águas em vários países do mundo, em virtude de suas altas cargas orgânicas, de sólidos e de nutrientes ( $\mathrm{N}$ e $\mathrm{P}$ ). No Brasil, com rebanho de suínos estimado em 36,5 milhões (ABCS, 1999), a produção concentra-se nas regiões Sul (34,1\% dos animais) e Sudeste (18,8\% dos animais). O problema mais grave ocorre no Estado de Santa Catarina, onde os resíduos de suinocultura são a maior fonte de poluição das águas.

A separação das frações sólida e líquida, de acordo com as recomendações de HOLMBERG et al. (1983), NG \& CHIN (1988), CHOU et al. (1995), será necessária para adotarem-se destinações individuais para cada fração do resíduo de suinocultura. A fração líquida que contém a maior parte dos compostos inorgânicos, tais como nitrogênio amoniacal e fósforo, e considerável potencial de produção de metano, ainda apresenta altas concentrações de sólidos suspensos (HOLMBERG et al., 1983).

Vários trabalhos foram desenvolvidos tratando a fração líquida dos resíduos de suinocultura em reatores anaeróbios de alta taxa (HASHEIDER \& SIEVERS, 1984; YANG \& CHOU, 1985; NG \& CHIN, 1988; ZHANG \& DAGUE, 1995, entre outros), entre eles, nos reatores UASB (CINTOLI et al., 1995; FORESTI \& OLIVEIRA, 1995, entre outros), alcançando boas remoções de DQO e sólidos, e bons rendimentos de metano.

Dessa forma, considerando-se a necessidade de conhecimento do desempenho de reatores UASB tratando águas residuárias complexas, no que diz respeito à concentração de SST, como as de suinocultura, e do destino das frações da matéria orgânica do afluente no processo de bioconversão anaeróbia, o objetivo deste trabalho foi realizar o balanço de massa, a partir dos valores de DQO e produção de metano, de reatores UASB tratando águas residuárias de suinocultura, com concentrações de SST de 500; $1.000 ; 1.500$ e $2.000 \mathrm{mg} \mathrm{L}^{-1}$.

\section{MATERIAL E MÉTODOS}

Cada unidade experimental foi composta por tanque de alimentação, bomba peristáltica, reator UASB de bancada, selo hídrico e gasômetro (Figura 1). Foram utilizadas, simultaneamente, duas dessas unidades, operadas sob condições diferentes, no Laboratório de Processos Anaeróbios da Escola de Engenharia de São Carlos, EESC/USP.

O reator UASB, com capacidade de 10,5 L, foi construído com duas faces paralelas, em acrílico, comprimidas contra o contorno das paredes laterais do reator, em aço inoxidável, e fixadas com parafusos.

O esterco bruto, coletado de um confinamento de suínos na fase de terminação, foi pré-diluído, homogeneizado à concentração de ST em torno de $1 \%$. O líquido foi então peneirado (malha quadrada 
com $1 \mathrm{~mm}$ de lado). Feito isto, foram tomadas amostras para análise de SST, o que tornou possível calcular os volumes de água a serem adicionados para se obterem as concentrações de SST desejadas.

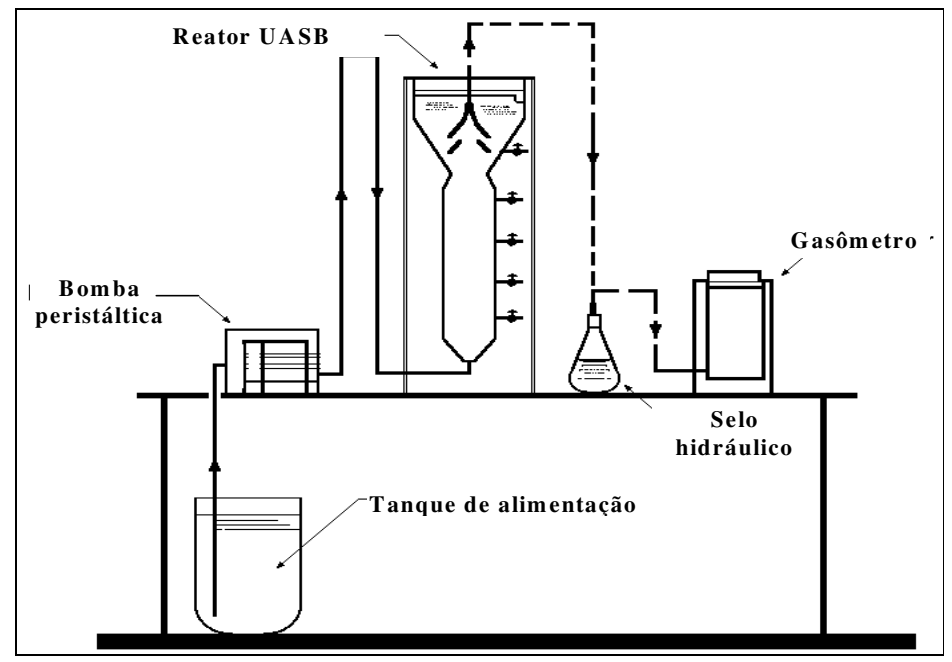

FIGURA 1. Esquema da unidade experimental.

O primeiro conjunto de experimentos, fase I, compreendeu a operação de dois reatores com afluentes com concentrações de SST ao redor de $500 \mathrm{mg} \mathrm{L}^{-1}$, reator 1 , e $1.000 \mathrm{mg} \mathrm{L}^{-1}$, reator 2 . No segundo conjunto, fase II, estas concentrações foram alteradas para $1.500 \mathrm{mg} \mathrm{L}^{-1}$, reator 1 , e $2.000 \mathrm{mg} \mathrm{L}^{-1}$, reator 2. Na Tabela 1, está apresentado o resumo das condições de operação dos reatores 1 e 2 , nas fases I e II.

Os procedimentos para partida incluíram a inoculação com lodo granular, de um reator UASB tratando resíduos de cervejaria, e operação com baixas cargas orgânicas e hidráulicas. Na sequiência, o TDH foi sendo diminuído, permitindo a operação com aumentos das taxas de carregamento (Tabela 1).

Esses experimentos foram conduzidos à temperatura ambiente no laboratório. A temperatura variou de $13{ }^{\circ} \mathrm{C}$, no inverno, a $33{ }^{\circ} \mathrm{C}$, no verão (Tabela 1). O efeito da temperatura sobre o desempenho dos reatores foi estudado na fase II com TDH de $12 \mathrm{~h}$, no inverno e início da primavera. As temperaturas testadas foram $25^{\circ}$ e $30^{\circ} \mathrm{C}$ (Tabela 1 ).

Diariamente, foram monitoradas a vazão, a produção de gás (em gasômetros) e a temperatura. Duas a três vezes por semana, foram determinadas a demanda química de oxigênio (DQO total) e a concentração de SST e de sólidos suspensos voláteis (SSV). A composição do gás foi analisada uma vez por semana, utilizando-se de cromatógrafo a gás equipado com coluna Poropak-Q, com temperatura de operação de $70{ }^{\circ} \mathrm{C}$. Todas as determinações foram realizadas de acordo com APHA et al. (1985).

Durante a realização da análise de SST, foi coletado o líquido filtrado e determinada sua DQO. Segundo APHA et al. (1985), esse líquido filtrado da análise de SST fornecerá a concentração de sólidos totais dissolvidos, o que conduziu a denominação de DQO dissolvida. O valor da DQO dissolvida, subtraído do valor da DQO total, forneceu os valores da DQO devido aos sólidos suspensos (DQO SS).

A partir dos valores médios da DQO total, DQO SS, DQO dissolvida e produção diária de $\mathrm{CH}_{4}$, nos reatores 1 e 2, nas fases I e II, determinaram-se as porcentagens da DQO total do afluente e removida, convertidas em $\mathrm{CH}_{4}$, e a relação entre a produção de $\mathrm{CH}_{4}$ medida e a DQO dissolvida removida. Adotando-se os procedimentos descritos por YANG \& CHOU (1985) e SAYED (1987), estimaram-se o valor da DQO acumulada na forma de lodo, subtraindo-se do valor da DQO total 
removida, a produção diária de $\mathrm{CH}_{4}$ medida; a eficiência de remoção física, dividindo-se o valor da DQO acumulada na forma de lodo pelo valor da DQO total removida; e o fator de acumulação de lodo no reator (Y acumulado), dividindo-se o valor da DQO acumulada na forma de lodo pela DQO total removida.

\section{RESULTADOS E DISCUSSÃO}

Os valores médios obtidos nas determinações da concentração de SST e DQO total do afluente, os valores do tempo de detenção hidraúlica (TDH), a taxa de carregamento orgânico volumétrico (TCOV), as temperaturas máximas e mínimas diárias no laboratório e a duração de cada etapa do experimento, durante a operação dos reatores 1 e 2, nas fases I e II, estão apresentados na Tabela 1.

TABELA 1. Condições de operação dos reatores UASB, com valores médios de algumas determinações.

\begin{tabular}{|c|c|c|c|c|c|c|c|}
\hline Fase & Reator & $\begin{array}{c}\text { Conc. de SST do } \\
\text { afluente } \\
\left(\mathrm{mg} \mathrm{L}^{-1}\right)\end{array}$ & $\begin{array}{l}\text { DQO total } \\
\text { do afluente } \\
\left(\mathrm{mg} \mathrm{L}^{-1}\right)\end{array}$ & $\begin{array}{c}\text { TDH } \\
\text { (h) }\end{array}$ & $\begin{array}{c}\text { TCOV } \\
\text { (a) }\end{array}$ & $\begin{array}{c}\text { Temp. máxima e } \\
\text { mínima diárias } \\
\left({ }^{\circ} \mathrm{C}\right)\end{array}$ & $\begin{array}{c}\text { Duração } \\
\text { (d) }\end{array}$ \\
\hline \multirow{8}{*}{ I } & \multirow{4}{*}{1} & 528 & 1.025 & 30 & 0,82 & 29,0 e 15,0 & 79 \\
\hline & & 476 & 952 & 20 & 1,14 & 29,0 e 17,0 & 35 \\
\hline & & 468 & 976 & 12 & 1,95 & 30,0 e 22,5 & 39 \\
\hline & & 467 & 1.078 & 8 & 3,23 & 29,5 e 22,5 & 56 \\
\hline & \multirow{4}{*}{2} & 1.081 & 2.025 & 30 & 1,63 & 29,0 e 15,0 & 79 \\
\hline & & 1.000 & 1.915 & 20 & 2,30 & 29,0 e 17,0 & 35 \\
\hline & & 926 & 1.959 & 12 & 3,92 & 30,0 e 22,5 & 39 \\
\hline & & 951 & 2.195 & 8 & 6,58 & 29,5 e 22,5 & 56 \\
\hline \multirow{10}{*}{ II } & \multirow{5}{*}{1} & 1.630 & 3.015 & 27 & 2,68 & 30,5 e 19,5 & 74 \\
\hline & & 1.431 & 2.820 & 20 & 3,38 & 27,5 e 19,5 & 46 \\
\hline & & 1.375 & 3.036 & 12 & 6,07 & 26,5 e 13,0 & 71 \\
\hline & & 1.493 & 2.932 & 12 & 5,86 & 28,5 e $23,5^{b}$ & 40 \\
\hline & & 1.435 & 2.812 & 12 & 5,72 & 33,0 e $27,0^{c}$ & 38 \\
\hline & \multirow{5}{*}{2} & 2.274 & 3.971 & 29 & 3,27 & 30,5 e 19,5 & 74 \\
\hline & & 1.889 & 3.544 & 20 & 4,25 & 27,5 e 19,5 & 46 \\
\hline & & 1.910 & 4.013 & 12 & 8,03 & 26,5 e 13,0 & 71 \\
\hline & & 1.978 & 3.832 & 12 & 7,66 & 28,5 e $23,5^{b}$ & 40 \\
\hline & & 1.993 & 3.709 & 12 & 7,42 & 33,0 e $27,0^{c}$ & 38 \\
\hline
\end{tabular}

$\mathrm{a}-\mathrm{kg}$ DQO total $\left(\mathrm{m}^{3} \mathrm{~d}\right)^{-1}$.

b e c - temperatura controlada a $25^{\circ} \mathrm{C}$ e $30^{\circ} \mathrm{C}$, respectivamente.

A apresentação e a discussão dos resultados de desempenho e características dos lodo dos reatores 1 e 2, nas fases I e II, foram feitas por FORESTI \& OLIVEIRA (1995) e OLIVEIRA et al. (1997). As eficiências de remoção de DQO e SST variaram de 72 a 95\%, as produções específicas e volumétrica de metano variaram de 0,10 a $0,18 \mathrm{~m}^{3} \mathrm{CH}_{4}\left(\mathrm{~kg}\right.$ DQO removida) ${ }^{-1}$ e de 0,072 a $1,151 \mathrm{~m}^{3}$ $\mathrm{CH}_{4}\left(\mathrm{~m}^{3} \text { reator } \mathrm{d}\right)^{-1}$, respectivamente. Os valores médios das eficiências de remoção de DQO total, DQO SS e DQO dissolvida estão apresentados nas Tabelas 2 e 5.

Observou-se que houve crescimento contínuo de lodo na zona de reação dos reatores, com predominância de grânulos com formato esférico irregular, de coloração preta e cinza nas regiões inferiores e superiores da manta, respectivamente. A concentração de SSV do lodo foi maior na região intermediária da manta e variou de 20 a $50 \mathrm{~g} \mathrm{~L}^{-1}$, com relação SSV/SST de 0,78 a 0,87. Os grânulos do lodo, observados em microscópio eletrônico de varredura, apresentaram distribuição das morfologias 
bacterianas de forma estruturada em três camadas, predominando na camada externa populações mistas de bactérias formando filamentos longos e finos, normalmente associadas às formadoras de ácidos e as hidrolíticas. A primeira camada interna do grânulo de lodo era formada por bacilos de diferentes tamanhos e observou-se menor heterogeneidade de morfologias bacterianas. A partir das camadas medianas, observou-se a presença de bacilos com as extremidades achatadas, semelhantes a "gomos de bambu", com dimensões aproximadas de 0,8 $\mu \mathrm{m}$ de diâmetro e 2,0 $\mu \mathrm{m}$ de comprimento, morfologia esta associada às arqueas metanogênicas do gênero Methanosaeta, cuja predominância ocorreu na camada central do grânulo de lodo (OLIVEIRA et al., 1997)

Nas Tabelas 2 e 3, estão apresentados, para os reatores 1 e 2, nas fases I e II, respectivamente, os resultados médios de produção diária de $\mathrm{CH}_{4}$, juntamente com a TCOV, as DQO médias diárias afluentes, efluentes e removidas, os valores calculados das porcentagens de DQO total afluente e removida convertidas em $\mathrm{CH}_{4}$ e a relação entre a produção medida de $\mathrm{CH}_{4}$ e a DQO dissolvida removida.

Na fase I, os valores de DQO total do afluente e removida, convertida em metano, variaram na média, respectivamente, de 25,2 a $32,1 \%$ e 28,1 a $36,0 \%$, para o reator 1 , e de 29,6 a $37,5 \%$ e 33,8 a 44,3\%, para o reator 2; na fase II, com operação à temperatura ambiente, variaram de 27,4 a $34,5 \%$ e 33,8 a $39,4 \%$, para o reator 1 , e de 25,1 a $33,7 \%$ e 32,0 a $38,7 \%$, para o reator 2 . Ainda na fase II, com $\mathrm{TDH}$ de $12 \mathrm{~h}$ e temperatura controlada a $25{ }^{\circ} \mathrm{C}$ e $30{ }^{\circ} \mathrm{C}$, foram, respectivamente, 34,1 e $37,2 \%$, e 41,6 e $44,1 \%$, no reator 1 , e 34,7 e $44,3 \%$, e 40,7 e $50,8 \%$, no reator 2 . O controle e o aumento da temperatura de operação a 25 e $30^{\circ} \mathrm{C}$ promoveram aumentos crescentes em relação à operação, à temperatura ambiente (de $13^{\circ}$ a $26,5^{\circ} \mathrm{C}$ ), com TDH de $12 \mathrm{~h}$. Entretanto, esses valores podem ser considerados baixos.

Deve-se ressaltar, porém, que ocorreram perdas de gás no separador de fases, além de perdas de $\mathrm{CH}_{4}$ dissolvido na fase líquida, cuja concentração depende da temperatura e da pressão parcial desse gás na fase gasosa (Lei de Henry). VAN HAANDEL \& LETTINGA (1994) citaram que, em virtude das perdas de $\mathrm{CH}_{4}$ no efluente e para a atmosfera, a produção medida é bem menor que aquela prevista com base em considerações estequiométricas, atingindo na prática valores de 20 a $50 \%$ da produção teórica de $\mathrm{CH}_{4}$.

Apesar disso, comparando-se esses valores com os apresentados na Tabela 4, obtidos por YANG \& CHOU (1985) tratando águas residuárias de suinocultura com características semelhantes às utilizadas nos reatores 1 e 2, na fase I, em reator anaeróbio com chicanas, os quais variaram de 6,68 a $14,06 \%$ (TCOV de 1,7 a 3,5 kg DQO total $\left(\mathrm{m}^{3} \mathrm{~d}\right)^{-1}$ ), para DQO total do afluente convertida em $\mathrm{CH}_{4}$, e de 8,04 a 25,16\%, para DQO total removida, convertida em $\mathrm{CH}_{4}$, observam-se as melhores conversões no reator UASB. As eficiências de remoção de DQO total nos reatores 1 e 2, na fase I, foram maiores, de 85 a 90\%, para TCOV de 0,82 a 3,92 kg DQO total $\left(\mathrm{m}^{3} \mathrm{~d}\right)^{-1}$ (Tabela 2), do que as observadas por YANG \& CHOU (1985), as quais variaram de 59,4 a 80,9\%.

Os valores obtidos por SAYED (1987), operando reatores UASB tratando águas residuárias de abatedouro, com concentrações de SST semelhantes às das águas residuárias de suinocultura utilizadas nos reatores 1 e 2, na fase I, apresentados na Tabela 4, para DQO total do afluente convertida em $\mathrm{CH}_{4}$ variaram numa faixa mais ampla (de 27 a $65 \%$ para TCOV de 0,9 a $6,4 \mathrm{~kg}$ DQO total $\left(\mathrm{m}^{3} \mathrm{~d}\right)^{-1}$ ), a qual abrange os resultados obtidos neste trabalho, ao passo que, para DQO total removida, convertida em metano, foram superiores (de 52 a $123 \%$ para TCOV de 1,5 a 6,2 $\mathrm{kg}$ DQO total $\left(\mathrm{m}^{3} \mathrm{~d}\right)^{-1}$ ).

Essa observação pode ser atribuída às seguintes condições observadas no trabalho de SAYED (1987): maiores proporções da DQO dissolvida em relação à DQO total do afluente nas águas residuárias de abatedouro, menores eficiências de remoção para DQO total, além da operação com temperatura maior $\left(30{ }^{\circ} \mathrm{C}\right)$ e mais constante $\left(20{ }^{\circ} \mathrm{C}\right.$ e $\left.30{ }^{\circ} \mathrm{C}\right)$. 
TABELA 2. Valores médios de DQO (total, dissolvida e SS) afluente, efluente e removida; produção diária de $\mathrm{CH}_{4}$; DQO total afluente e removida convertidas em $\mathrm{CH}_{4}$; e relação entre produção de $\mathrm{CH}_{4} \mathrm{e}$ DQO dissolvida removida, nos reatores 1 e 2. na fase I.

\begin{tabular}{|c|c|c|c|c|c|c|c|c|c|}
\hline \multirow{2}{*}{$\begin{array}{c}\text { Fase/ } \\
\text { Rea } \\
\text { tor }\end{array}$} & \multirow[b]{2}{*}{$\begin{array}{l}\text { TDH } \\
\text { (h) }\end{array}$} & \multirow[b]{2}{*}{$\begin{array}{c}\mathrm{TCOV} \\
\text { (a) }\end{array}$} & $\begin{array}{c}\text { Afluente } \\
\text { DQO total }\end{array}$ & $\begin{array}{c}\text { Efluente } \\
\text { DQO total }\end{array}$ & $\begin{array}{l}\text { Remoção } \\
\text { DQO total }\end{array}$ & \multirow{2}{*}{$\begin{array}{c}\text { Produção } \\
\text { diária } \\
\text { de } \mathrm{CH}_{4} \\
\left(\mathrm{~g} \mathrm{DQO}^{-}\right. \\
\left.\mathrm{CH}_{4} \mathrm{~d}^{-1}\right)\end{array}$} & \multirow{2}{*}{$\begin{array}{l}\text { DQO total } \\
\text { do afluente } \\
\text { convertida } \\
\mathrm{em} \mathrm{CH}_{4}(\%)\end{array}$} & \multirow{2}{*}{ 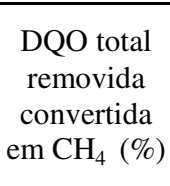 } & \multirow{2}{*}{$\begin{array}{l}\text { Relação } \\
\text { DQO- } \mathrm{CH}_{4} / \\
\text { DQO dis. } \\
\text { removida }\end{array}$} \\
\hline & & & $\begin{array}{c}\text { DQO SS DQO } \\
\text { dis. } \\
\left(\mathrm{g} \mathrm{d}^{-1}\right)\end{array}$ & $\begin{array}{c}\text { DQO DQO } \\
\text { SS dis. } \\
\left(\mathrm{g} \mathrm{d}^{-1}\right)\end{array}$ & $\begin{array}{l}\text { DQO DQO } \\
\text { SS dis. } \\
\left(\mathrm{g} \mathrm{d}^{-1} \mathrm{e} \%\right)\end{array}$ & & & & \\
\hline \multirow{8}{*}{$\mathrm{I} / 1$} & 30 & 0,82 & 8,614 & 0,887 & $7,727(90)$ & 2,169 & 25,2 & 28,1 & 0,94 \\
\hline & & & 2,948 & 0,257 & $5,409(96)$ & & & & \\
\hline & 20 & 1,14 & 11,996 & 1,282 & $10,714(89)$ & 3,854 & 32,1 & 36,0 & 1,30 \\
\hline & & & $8,140 \quad 3,856$ & $0,387 \quad 0,895$ & $2,961(77)$ & & & & \\
\hline & 12 & 1,95 & 20,504 & 2,161 & $18,343(90)$ & 5,671 & 27,7 & 30,9 & 1,21 \\
\hline & & & $14,603 \quad 5,901$ & $0,943 \quad 1,218$ & $13,660(94) \quad 4,683(79)$ & & & & \\
\hline & 8 & 3,23 & 33,961 & 5,097 & $28,864(85)$ & 9,266 & 27,3 & 32,1 & 1,46 \\
\hline & & & $25,109 \quad 8,852$ & $2,608 \quad 2,489$ & $22,501(90) \quad 6,363(72)$ & & & & \\
\hline \multirow{8}{*}{$\mathrm{I} / 2$} & 30 & 1,63 & 17,010 & 2,118 & $14,892(88)$ & 5,040 & 29,6 & 33,8 & 1,14 \\
\hline & & & $11,441 \quad 5,569$ & $0,984 \quad 1,134$ & $10,457(91) \quad 4,435(81)$ & & & & \\
\hline & 20 & 2,30 & 24,129 & 3,688 & $20,441(85)$ & 9,057 & 37,5 & 44,3 & 1,62 \\
\hline & & & $16,846 \quad 7,283$ & $2,012 \quad 1,676$ & $14,834(88) \quad 5,607(77)$ & & & & \\
\hline & 12 & 3,92 & 41,141 & 5,170 & $35,971(88)$ & 13,634 & 33,1 & 37,9 & 1,59 \\
\hline & & & $30,200 \quad 10,941$ & 2,818 & $27,832(92) \quad 8,589(79)$ & & & & \\
\hline & 8 & 6,58 & 69,143 & 12,946 & $56,197(81)$ & 23,549 & 34,1 & 41,9 & 1,99 \\
\hline & & & $53,078 \quad 16,065$ & 8,725 & $44,353(84) \quad 11,844(73)$ & & & & \\
\hline
\end{tabular}

$\overline{\mathrm{a}-\text { unidade: } \mathrm{kg} \text { DQO total }\left(\mathrm{m}^{3} \mathrm{~d}\right)^{-1}}$

TABELA 3. Valores médios de DQO (total, dissolvida e SS) afluente, efluente e removida; produção diária de $\mathrm{CH}_{4}$; DQO total afluente e removida convertidas em $\mathrm{CH}_{4}$; e relação entre produção de $\mathrm{CH}_{4}$ e DQO dissolvida removida, nos reatores 1 e 2, na fase II.

\begin{tabular}{|c|c|c|c|c|c|c|c|c|c|c|c|c|}
\hline \multirow{2}{*}{$\begin{array}{c}\text { Fase/ } \\
\text { Rea } \\
\text { tor }\end{array}$} & \multirow[b]{2}{*}{$\begin{array}{l}\text { TDH } \\
\text { (h) }\end{array}$} & \multirow[b]{2}{*}{$\begin{array}{l}\text { TCOV } \\
\text { (a) }\end{array}$} & \multicolumn{2}{|c|}{$\begin{array}{c}\text { Afluente } \\
\text { DQO total }\end{array}$} & \multicolumn{2}{|c|}{$\begin{array}{c}\text { Efluente } \\
\text { DQO total }\end{array}$} & \multicolumn{2}{|c|}{$\begin{array}{l}\text { Remoção } \\
\text { DQO total }\end{array}$} & \multirow{2}{*}{$\begin{array}{c}\text { Produção } \\
\text { diária } \\
\text { de } \mathrm{CH}_{4} \\
\left(\mathrm{~g} \mathrm{DQO}^{-}\right. \\
\left.\mathrm{CH}_{4} \mathrm{~d}^{-1}\right) \\
\end{array}$} & \multirow{2}{*}{$\begin{array}{l}\text { DQO total } \\
\text { do afluente } \\
\text { convertida } \\
\text { em } \mathrm{CH}_{4}(\%)\end{array}$} & \multirow{2}{*}{$\begin{array}{l}\text { DQO total } \\
\text { removida } \\
\text { convertida } \\
\text { em } \mathrm{CH}_{4}(\%)\end{array}$} & \multirow{2}{*}{$\begin{array}{c}\text { Relação } \\
\text { DQO-CH} \\
/ \\
\text { DQO dis. } \\
\text { removida } \\
\end{array}$} \\
\hline & & & $\begin{array}{l}\text { DQO } \\
\text { SS } \\
\quad(g \\
\end{array}$ & $\begin{array}{l}\text { DQO } \\
\text { dis. } \\
\text { 1) }\end{array}$ & $\begin{array}{l}\text { DQO } \\
\mathrm{SS} \\
\quad(\mathrm{gc}\end{array}$ & $\begin{array}{l}\text { DQO } \\
\text { dis. } \\
1 \text { ) }\end{array}$ & $\begin{array}{l}\text { DQO } \\
\text { SS } \\
\quad\left(\mathrm{g} \mathrm{d}^{-}\right.\end{array}$ & $\begin{array}{l}\text { DQO } \\
\text { dis. } \\
\left.\mathrm{e}^{\mathrm{\%}}\right)^{\mathrm{P}}\end{array}$ & & & & \\
\hline \multirow{10}{*}{ II/1 } & 27 & 2,68 & \multicolumn{2}{|c|}{28,140} & \multicolumn{2}{|c|}{2,260} & \multicolumn{2}{|c|}{$25,880(92)$} & 9,037 & 32,1 & 35,0 & 2,02 \\
\hline & & & 22,448 & 5,692 & 1,042 & 1,218 & $21,406(95)$ & $4,474(79)$ & & & & \\
\hline & 20 & 3,38 & \multicolumn{2}{|c|}{35,535} & \multicolumn{2}{|c|}{4,407} & \multicolumn{2}{|c|}{$31,128(88)$} & 12,266 & 34,5 & 39,4 & 2,07 \\
\hline & & & 27,698 & 7,837 & 2,504 & 1,903 & $25,194(91)$ & $5,934(76)$ & & & \multirow{3}{*}{33,8} & \multirow{3}{*}{1,85} \\
\hline & 12 & 6,07 & \multicolumn{2}{|c|}{63,755} & \multicolumn{2}{|c|}{12,137} & \multicolumn{2}{|c|}{$51,618(81)$} & \multirow[t]{2}{*}{17,440} & \multirow[t]{2}{*}{27,4} & & \\
\hline & & & 50,861 & 12,894 & 8,693 & 3,444 & $42,168(83)$ & $9,450(73)$ & & & & \\
\hline & $12^{\mathrm{b}}$ & 5,86 & \multicolumn{2}{|c|}{61,574} & \multicolumn{2}{|c|}{11,085} & \multicolumn{2}{|c|}{$50,489(82)$} & \multirow[t]{2}{*}{21,023} & \multirow[t]{2}{*}{34,1} & 41,6 & 1,73 \\
\hline & & & 45,404 & 16,170 & 7,074 & 4,011 & $38,330(84)$ & $12,159(75)$ & & & & \\
\hline & $12^{\mathrm{c}}$ & 5,72 & & & 9,2 & & 49,8 & $(84)$ & 21,971 & 37,2 & 44,1 & 1,92 \\
\hline & & & 43,290 & 15,771 & 4,883 & 4,347 & $38,407(89)$ & $11,424(73)$ & & & & \\
\hline & 29 & 3,27 & & & 3,3 & & 31,1 & $3(90)$ & 11,989 & 33,7 & 38,5 & 1,75 \\
\hline & & & 27,175 & 8,369 & 1,872 & 1,514 & $24,303(89)$ & $6,855(82)$ & & & & \\
\hline & 20 & 4,25 & & & 5,8 & & 38,8 & $(87)$ & 15,037 & 33,7 & 38,7 & 1,65 \\
\hline & & & 33,285 & 11,365 & 3,534 & 2,268 & $29,751(89)$ & $9,097(80)$ & & & & \\
\hline IJ/2 & 12 & 8,03 & & & 21, & & 63,1 & $5(75)$ & 20,191 & 25,1 & 32,0 & 1,40 \\
\hline $111 / 2$ & & & 65,586 & 18,690 & 16,827 & 4,263 & 48,759 (79) & $14,427(77)$ & & & & \\
\hline & $12^{\mathrm{b}}$ & 7,66 & 80 & & 11,8 & & 68,5 & $(85)$ & 27,914 & 34,7 & 40,7 & 1,34 \\
\hline & & & 55,304 & 25,158 & 7,518 & 4,368 & $47,786(86)$ & $20,790(82)$ & & & & \\
\hline & $12^{\mathrm{c}}$ & 7,42 & & & 9,9 & & 67,9 & $(87)$ & 34,517 & 44,3 & 50,8 & 1,78 \\
\hline & & & 53,828 & 24,066 & 5,290 & 4,641 & 48,538 (90) & $19,425(81)$ & & & & \\
\hline
\end{tabular}

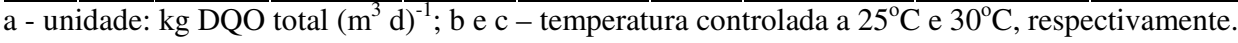

Isso pode ser evidenciado considerando-se que a produção volumétrica de $\mathrm{CH}_{4}$, na fase I, no reator 1 , foi de 0,206 a $0,883 \mathrm{~kg}$ DQO-CH ${ }_{4}\left(\mathrm{~m}^{3} \mathrm{~d}\right)^{-1}$, para TCOV de 0,82 a $3,23 \mathrm{~kg}$ DQO total $\left(\mathrm{m}^{3} \mathrm{~d}\right)^{-1}$, e no reator 2 de 0,480 a $2,243 \mathrm{~kg}$ DQO- $\mathrm{CH}_{4}\left(\mathrm{~m}^{3} \cdot \mathrm{d}\right)^{-1}$, para TCOV de 1,63 a 6,58 kg DQO total $\left(\mathrm{m}^{3} \mathrm{~d}\right)^{-1}$; ao passo que, SAYED (1987) também observou valores superiores, de 0,30 a 3,20 kg DQO- 
$\mathrm{CH}_{4}\left(\mathrm{~m}^{3} \mathrm{~d}\right)^{-1}$ para TCOV de 0,9 a $6,4 \mathrm{~kg}$ DQO total $\left(\mathrm{m}^{3} \mathrm{~d}\right)^{-1}$ (Tabela 4). Observou-se que o reator UASB com lodo granulado proporcionou maiores valores de produção de metano e, conseqüentemente, maiores conversões de DQO total removida. Isto foi verificado por meio da comparação entre os valores obtidos no reator 2, na fase I, (Tabela 2) e os apresentados por SAYED (1987), para o reator UASB com lodo floculento (TCOV de 1,8 a $5,4 \mathrm{~kg}$ DQO total $\left(\mathrm{m}^{3} \mathrm{~d}\right)^{-1}$ ), e também considerando-se os resultados de SAYED (1987) para o reator UASB com lodo granulado em relação ao com lodo floculento (Tabela 4).

Na Tabela 4, estão os valores obtidos por YANG \& CHOU (1985), tratando águas residuárias de suinocultura com características semelhantes às utilizadas no reator 1, na fase II, os quais foram, respectivamente, de 28,88 e 24,24\%, para DQO total do afluente convertida em metano, e de 53,92 e 40,33\%, para DQO total removida convertida em metano, para TCOV de 1,2 e 2,1 kg DQO total $\left(\mathrm{m}^{3} \mathrm{~d}\right)^{-1}$. Observa-se que estas conversões foram semelhantes em relação à DQO total do afluente e superiores em relação à DQO total removida. Entretanto, a eficiência de remoção de DQO total para o reator 1, na fase II, operado à temperatura ambiente, foi 92\%, nessa faixa de TCOV (Tabela 3), ao passo que, YANG \& CHOU (1958) observaram valores de 58,2 e 87,6\% para remoção de DQO total e SST, respectivamente. Os resultados no reator de chicanas (YANG \& CHOU, 1985) foram obtidos com maiores TDH (48 e 72 h), os quais propiciam melhores condições para a solubilização dos sólidos orgânicos.

Os valores obtidos por SAYED (1987), operando reatores UASB tratando águas residuárias de abatedouro, com concentrações de SST semelhantes às das águas residuárias de suinocultura utilizadas nos reatores 1 e 2, na fase II, apresentados na Tabela 4, para DQO total do afluente e DQO total removida convertidos em metano (36,7 e 44,4\%, respectivamente, para TCOV de 2,5 a 5,0 kg DQO total $\left.\left(\mathrm{m}^{3} \mathrm{~d}\right)^{-1}\right)$, foram pouco superiores aos resultados obtidos neste trabalho, com operação à temperatura ambiente. Essa constatação pode ser atribuída às mesmas condições citadas para a fase I em relação ao trabalho de SAYED (1987), evidenciado-se que a produção volumétrica de $\mathrm{CH}_{4}$, no reator 1 , foi de 0,860 a $1,660 \mathrm{~kg}$ DQO- $\mathrm{CH}_{4}\left(\mathrm{~m}^{3} \mathrm{~d}\right)^{-1}$ para TCOV de 2,68 a 6,07 kg DQO total $\left(\mathrm{m}^{3} \mathrm{~d}\right)^{-1}$, ao passo que, SAYED (1987) observou valores superiores, de 0,60 a 2,60 kg DQO- $\mathrm{CH}_{4}\left(\mathrm{~m}^{3} \mathrm{~d}\right)^{-1}$ para TCOV de 2,5 a 5,0 kg DQO total $\left(\mathrm{m}^{3} \mathrm{~d}\right)^{-1}$.

Comparando-se os valores observados na fase II, com TDH de $12 \mathrm{~h}$ e temperatura controlada à $25^{\circ} \mathrm{C}$ e $30^{\circ} \mathrm{C}$, com os obtidos por YANG \& CHOU (1985) e SAYED (1987), observam-se conversões semelhantes em relação à DQO total do afluente e DQO total removida, no reator 1 (Tabela 3). Devese ressaltar que os resultados no reator de chicanas (YANG \& CHOU, 1985) foram obtidos com maiores TDH, as eficiências de remoção de DQO total foram menores (46,4 e 58,2\%) e a temperatura de operação foi $30{ }^{\circ} \mathrm{C}$. No reator UASB (SAYED, 1987), houve maiores proporções da DQO dissolvida em relação à DQO total do afluente nas águas residuárias de abatedouro, eficiências de remoção de DQO total semelhantes $(82,3 \%)$, menores TCOV aplicadas e temperatura de operação de $30{ }^{\circ} \mathrm{C}$.

Os valores de conversão de DQO em metano observados no reator 2, na fase II, operado à temperatura ambiente e controlada a $25^{\circ} \mathrm{C}$ e $30{ }^{\circ} \mathrm{C}$ (Tabela 3), comparados com os obtidos por FANG \& KWONG (1994) e KWONG \& FANG (1996), apresentados na Tabela 4, operando reatores UASB e híbrido de UASB com águas residuárias contendo amido de milho, com concentrações de SST semelhantes, os quais foram, na média, respectivamente, para DQO total removida convertida em metano de $82,7 \%$ (TCOV de 3 a $10 \mathrm{~kg}$ DQO total $\left(\mathrm{m}^{3} \mathrm{~d}\right)^{-1}$ ) e 85,9\% (TCOV de 3 a $150 \mathrm{~kg}$ DQO total $\left.\left(\mathrm{m}^{3} \mathrm{~d}\right)^{-1}\right)$, observa-se que essas conversões foram bastante superiores. Para justificar essas diferenças, devem-se ressaltar as observações dos autores quanto à natureza de fácil biodegradação do amido de milho, contido na água residuária, a construção nos reatores de separadores de fase bastante eficientes e a temperatura de operação de $37{ }^{\circ} \mathrm{C}$. 
TABELA 4. Valores médios de DQO total do afluente e removida convertidas em $\mathrm{CH}_{4}$, relação DQO$\mathrm{CH}_{4}$ por DQO filtrada removida, fator de acumulação de lodo no reator (Y acumulado), eficiência de remoção física do reator e produção volumétrica de $\mathrm{CH}_{4}$ em reatores anaeróbios de alta taxa operados em condições semelhantes aos reatores 1 e 2, nas fases I e II.

Fa- Descrição da publicação Temp.

se (tipo de reator, água residuária e oper.

(a) outras informações necessárias) $\left({ }^{\circ} \mathrm{C}\right)$
TCOV

(b)
DQO total do DQO total Relação DQOafluente removida $\mathrm{CH}_{4}$ por DQO convertida em convertida em $\mathrm{CH}_{4}(\%) \quad \mathrm{CH}_{4}(\%)$ filtrada removida
Y Eficiência Produção acumulado remoção volumétrica

(c) física (\%) de $\mathrm{CH}_{4}{ }^{(\mathbf{d})}$

-SAYED (1987) - reator UASB

- águas residuárias: abatedouro

- com lodo floculento: $\quad 20 \quad 1,5$ a 2,5

(operação intermitente)

201,8 a 5,4

I

- com lodo granulado:

$30 \quad 0,5$ a 1,5

$30 \quad 0,9$ a 3,4

$30 \quad 2,5$ a 3,5

(operação contínua)

201,8 a 6,4

203,0 a 5,0

206,0 a 8,0

$30 \quad 1,6$ a 6,4

$30 \quad 2,5$ a 6,2

II - com lodo floculento:

$30 \quad 4,0$ a 5,0
62,8

27,0 a 43,1

37,8 a 39,6

36,0 a 47,9

39,0 a 54,0

33,8 a 50,9

40,0 a 65,0
54,2

57,8

52 a 88

(52)

73 a 123

36,7

44,4

19,24

8,04

9,94

25,16

53,92

40,33

82,70

- FANG \& KWONG (1994) e

II KWONG \& FANG (1996) -

reator UASB e híbrido de

UASB - águas residuárias contendo amido de milho

II - NG \& CHIN (1988) - reator $30 \quad 2,1$

de filme fixo e leito

expandido - águas residuárias suinocultura

II - ZHANG \& DAGUE (1995) $25 \quad 1,5$

- reator anaeróbio seqüencial em batelada - águas residuárias de suinocultura.

85,90

29,4 a 38,3
0,80 a 1,40

0,30 a 1,40

0,63 a 2,58

0,68 a 3,20

1,03 a 1,48

1,14 a $1,21 \quad 0,16$

0,11

0,15

0,60 a 2,60

0,47 a 0,63

- condições de operação semelhantes às aplicad
removida $)^{-1} ; \mathrm{d}$ unidade: $\mathrm{g}$ DQO- $\mathrm{CH}_{4}\left(\mathrm{~m}^{3} \mathrm{~d}\right)^{-1}$

Os resultados alcançados por NG \& CHIN (1988), operando reator de filme fixo e leito expandido tratando águas residuárias de suinocultura com características semelhantes à utilizada no reator 2, na fase II, possibilitaram estimar na média de 29,4 a 38,3\% da DQO total removida, convertida em metano (Tabela 4), para TCOV média de 2,1 $\mathrm{kg}$ DQO total $\left(\mathrm{m}^{3} \mathrm{~d}\right)^{-1}$, resultados esses semelhantes aos apresentados na Tabela 3, com operação à temperatura ambiente, e inferiores aos observados com temperatura controlada a $25{ }^{\circ} \mathrm{C}$ e $30{ }^{\circ} \mathrm{C}$, apesar da operação com TCOV maiores. A eficiência de remoção de DQO total no reator 2, na fase II, foi de $90 \%$, nesta faixa de TCOV, ao passo que, NG \& CHIN (1988) observaram 78\%.

Por outro lado, os resultados obtidos por ZHANG \& DAGUE (1995), operando reator seqüencial em batelada tratando águas residuárias de suinocultura com características semelhantes à utilizada no reatores 2, na fase II, indicaram estimativa média de $97 \%$ da DQO total removida, convertida em metano, para TCOV de 1,47 kg DQO total $\left(\mathrm{m}^{3} \mathrm{~d}\right)^{-1}$, valor bastante superior ao do reator 2 . No entanto, devem-se destacar o TDH de 3 dias e o tipo de reator (seqüencial em batelada), favorecendo a 
digestão dos sólidos orgânicos alimentados e retidos no lodo. As eficiências de remoção de DQO total e SV observadas por ZHANG \& DAGUE (1995) foram 59 e 54\%, respectivamente.

Essas considerações também podem ser evidenciadas a partir da produção volumétrica de $\mathrm{CH}_{4}$ no reator 2, na fase II, a qual foi de 1,143 a 3,289 $\mathrm{kg} \mathrm{DQO}-\mathrm{CH}_{4}\left(\mathrm{~m}^{3} \mathrm{~d}\right)^{-1}$, para TCOV de 3,27 a 8,03 kg DQO total $\left(\mathrm{m}^{3} \mathrm{~d}\right)^{-1}$, ao passo que, NG \& CHIN (1988) observaram valores médios de 0,474 a $0,629 \mathrm{~kg}$ DQO- $\mathrm{CH}_{4}\left(\mathrm{~m}^{3} \mathrm{~d}\right)^{-1}$, para TCOV de 2,07 kg DQO total $\left(\mathrm{m}^{3} \mathrm{~d}\right)^{-1}$, e ZHANG \& DAGUE (1995) observaram valores médios de $0,843 \mathrm{~kg}$ DQO- $\mathrm{CH}_{4}\left(\mathrm{~m}^{3} \mathrm{~d}\right)^{-1}$, para TCOV de 1,47 kg DQO total $\left(\mathrm{m}^{3} \mathrm{~d}\right)^{-1}$.

Observa-se, na Tabela 2, que a relação DQO- $\mathrm{CH}_{4}$ por DQO dissolvida removida, na fase I, no reator 1, variou de 0,94 a 1,46; e no reator 2, de 1,14 a 1,99; ao passo que SAYED (1987) obteve valores de 0,87 a 1,67 (Tabela 4). Isso demonstra que, proporcionalmente, houve maior produção de metano a partir das águas residuárias de suinocultura, além da proveniente da DQO dissolvida do afluente, portanto a partir da solubilização de componentes da DQO SS.

$\mathrm{Na}$ fase II, com operação à temperatura ambiente, a relação DQO- $\mathrm{CH}_{4}$ por DQO dissolvida removida (Tabela 3) variou de 1,85 a 2,07, para o reator 1, e de 1,40 a 1,75, para o reator 2. Os valores obtidos no reator 2 foram inferiores aos do reator 1, como ocorreu também na fase I, demonstrando que as maiores concentrações de SST do afluente influenciaram na produção de metano, além da proveniente da DQO dissolvida do afluente. Portanto, houve diminuição na solubilização de componentes da DQO devido à fração de SS, o que ocorreu de forma mais acentuada com a queda da temperatura de operação e aumento da TCOV verificados com TDH de $12 \mathrm{~h}$ (Tabelas 2 e 3).

Nos reatores 1 e 2, com TDH de 12 h e temperatura de operação de $25^{\circ} \mathrm{C}$, os valores de DQO$\mathrm{CH}_{4}$ por DQO dissolvida removida diminuíram, respectivamente, para 1,73 e 1,34; em relação à operação à temperatura ambiente e a $30{ }^{\circ} \mathrm{C}$, aumentaram para 1,92 e 1,78. Isso demonstrou que a solubilização de componentes da DQO, devido à fração de SS, aumentou somente com a temperatura de $30{ }^{\circ} \mathrm{C}$, em virtude de terem melhorado as condições para hidrólise e para produção de metano. Os valores observados no reator 2 também foram menores do que no reator 1, com temperatura controlada a $25{ }^{\circ} \mathrm{C}$ e $30{ }^{\circ} \mathrm{C}$, podendo-se atribuir as maiores TCOVs em relação à DQO dissolvida e também as possíveis maiores taxas de hidrólise ocorridas no reator 2 , conduzindo à acumulação de compostos solúveis.

SAYED (1987) obteve, para a relação DQO- $\mathrm{CH}_{4}$ por DQO dissolvida removida, valor médio de 1,98 com TCOV de 2,5 a 5,0 kg DQO total $\left(\mathrm{m}^{3} \mathrm{~d}\right)^{-1}$ (Tabela 4). Comparando-se com os resultados apresentados na Tabela 3, na fase II, observa-se que os valores obtidos para as águas residuárias de suinocultura foram semelhantes, no reator 1, e inferiores, no reator 2, aos apresentados para águas residuárias de abatedouro, a qual apresenta maior participação da DQO filtrada na DQO total.

Essa inversão na tendência observada na fase I pode ter sido ocasionada pelo aumento da concentração de SST do afluente, para valores médios em torno de 1.500 e $2.000 \mathrm{mg} \mathrm{L}^{-1}$, respectivamente, nos reatores 1 e 2 , na fase II.

A partir dos resultados obtidos neste trabalho, para os reatores 1 e 2, nas fases I e II, e os apresentados por SAYED (1987), FANG \& KWONG (1994) e KWONG \& FANG (1996), observa-se que a conversão da DQO em metano, no reator UASB, independentemente da água residuária está associada à temperatura de operação, à participação da DQO dissolvida na DQO total do afluente, acrescentando-se as características de biodegradabilidade dos SSTs presentes no afluente. OLIVEIRA et al. (1996) observaram que, com temperaturas mais altas e mais estáveis, o desempenho dos reatores UASB melhorou. As eficiências de remoção e produção de metano, assim obtidas, podem equivaler e/ou superar as condições de menores TDH (conseqüentemente menores TCOVs), em virtude da influência da temperatura na solubilização dos sólidos orgânicos e crescimento dos microrganismos, conseqüentemente melhorando as condições para a metanogênese. Isto para reatores semelhantes, com 
alimentação contínua, e com as águas residuárias com altas concentrações de SST com biodegradabilidade semelhante, em virtude de a influência da temperatura na solubilização dos sólidos orgânicos também depender da sua natureza.

No que diz respeito às águas residuárias de suinocultura, a conversão contínua será influenciada pelo tipo de reator. Os reatores UASB apresentaram melhor desempenho em relação ao reator anaeróbio de chicanas (YANG \& CHOU, 1985), o de filme fixo e leito expandido (NG \& CHIN, 1988) e o filtro anaeróbio (HASHEIDER \& SIEVERS, 1984), operando em condições semelhantes aos reatores 1 e 2, nas fases I e II, mesmo com maiores valores de temperatura em alguns deles.

Foi observado que, para TDH e temperaturas mais altas, o desempenho é melhorado, independentemente do tipo de reator, com alimentação contínua, e da água residuária com altas concentrações de SST. Isso em virtude da influência de ambos os fatores sobre a solubilização dos sólidos orgânicos. Por outro lado, considerando-se os resultados obtidos por ZHANG \& DAGUE (1995), o reator seqüencial em batelada parece favorecer esse passo do processo da digestão anaeróbia, porque apresentou conversão da DQO total removida em metano bastante superior aos outros reatores, em virtude de proporcionar maiores tempos de retenção de sólidos (TRS).

Considerando-se estes resultados de conversão de DQO em metano, o efeito da temperatura e do aumento da concentração de SST no afluente sobre o crescimento da manta de lodo (OLIVEIRA et al., 1997), e da mesma forma que foi evidenciado por SAYED (1987) e YANG \& CHOU (1985), ressaltase a importância da acumulação de lodo nos reatores.

SAYED (1987), em reatores UASB com lodo floculento e granulado, estimou um fator de acumulação de lodo no reator (Y acumulado), encontrando valores de 0,06 a 0,50 g SSV (g DQO total removida $)^{-1}$, para TCOV de 0,5 a 8,0 kg DQO total $\left(\mathrm{m}^{3} \mathrm{~d}\right)^{-1}$, e valor médio de $0,39 \mathrm{~g} \mathrm{SSV} \mathrm{(g} \mathrm{DQO}$ total removida) ${ }^{-1}$ para TCOV de 2,5 a 5,0 kg DQO total $\left(\mathrm{m}^{3} \mathrm{~d}\right)^{-1}$ (Tabela 4), quando operou os reatores UASB tratando águas residuárias de abatedouro, com concentrações de SST semelhantes às das águas residuárias de suinocultura utilizadas nos reatores 1 e 2, nas fases I e II, respectivamente.

Esse fator (Y acumulado) foi obtido a partir do valor da DQO do lodo acumulado no reator (o qual foi igual a diferença entre a DQO total removida e a produção de metano (DQO-CH 4$)$ ) dividido pelo valor da DQO total removida. Com esse procedimento, SAYED (1987) não considerou as possíveis perdas de gás, conseqüentemente incorporando-as no Y acumulado, majorando-o.

YANG \& CHOU (1985) adotaram procedimento semelhante para a obtenção do que chamaram de eficiência de remoção física do reator, obtendo valores de 74,5 a 80,6\% da DQO total removida, acumulando-se no reator, para TCOV de 1,7 a 3,5 kg DQO total $\left(\mathrm{m}^{3} \mathrm{~d}\right)^{-1}$, e de $46,1 \%$ e 59,7\% para TCOV de 1,24 e 2,05 kg DQO total $\left(\mathrm{m}^{3} \mathrm{~d}\right)^{-1}$ (Tabela 4), tratando águas residuárias de suinocultura com características semelhantes às utilizadas nos reatores 1 e 2 , nas fases I e II, respectivamente.

Adotando-se procedimentos semelhantes aos de SAYED (1987) e YANG \& CHOU (1985), para estimativas de acumulação de lodo nos reatores, na fase I (Tabela 5), tem-se valores inferiores (de 56 a 72\%) aos apresentados por YANG \& CHOU (1985) e abrangidos na faixa (de 0,38 a 0,49 g SSV (g DQO removida) $^{-1}$ ) encontrada por SAYED (1987).

$\mathrm{Na}$ fase II (Tabela 5), têm-se valores semelhantes nos reatores 1 e 2, decrescentes com o aumento da temperatura, evidenciando a melhoria nas condições de hidrólise e metanogênese, diminuindo a remoção física nos reatores e, conseqüentemente, a acumulação de lodo na manta por este mecanismo. Com operação à temperatura ambiente, têm-se valores pouco superiores (eficiência de remoção física de 61 a $68 \%$ e Y acumulado de 0,41 a 0,46 g SSV (g DQO total removida) ${ }^{-1}$ ) aos apresentados por YANG \& CHOU (1985) e SAYED (1987). Porém, deve-se ressaltar os maiores TDH e temperatura constante utilizadas no reator de chicanas (YANG \& CHOU, 1985) e a temperatura maior e mais constante na operação do reator UASB com águas residuárias de abatedouro (SAYED, 
1987). Com TDH de $12 \mathrm{~h}$ e temperatura controlada a $25^{\circ} \mathrm{C}$ e $30^{\circ} \mathrm{C}$, tem-se que os valores foram semelhantes (remoção física de 49 a $59 \%$ e Y acumulado de 0,33 a 0,40 g SSV (g DQO total removida $)^{-1}$ ) aos apresentados por YANG \& CHOU (1985) e SAYED (1987). Porém, devem-se ressaltar os maiores TDHs utilizados no reator de chicanas (YANG \& CHOU, 1985).

TABELA 5. Valores médios de DQO total removida, produção diária de metano $\left(\mathrm{CH}_{4}\right)$ medida, DQO acumulada no reator na forma de lodo, eficiência de remoção física do reator, fator de acumulação de lodo no reator (Y acumulado), determinados de acordo com os procedimentos adotados por SAYED (1987) e YANG \& CHOU (1985), nos reatores 1 e 2, nas fases I e II.

\begin{tabular}{|c|c|c|c|c|c|c|c|c|}
\hline Fase & Reator & $\begin{array}{c}\text { TDH } \\
\text { (h) }\end{array}$ & $\begin{array}{c}\text { TCOV } \\
\text { (a) }\end{array}$ & $\begin{array}{l}\text { DQO total } \\
\text { removida } \\
\left(\mathrm{g} \mathrm{d}^{-1}\right)\end{array}$ & $\begin{array}{l}\text { Produção diária } \\
\text { de } \mathrm{CH}_{4} \text { medida } \\
\left(\mathrm{g} \mathrm{DQO}^{-} \mathrm{CH}_{4} \mathrm{~d}^{-1}\right)\end{array}$ & $\begin{array}{l}\text { DQO acumulada } \\
\text { na forma de lodo } \\
\left(\mathrm{g} \text { DQO total d } \mathrm{d}^{-1}\right)\end{array}$ & $\begin{array}{l}\text { Efic. de re- } \\
\text { moção física } \\
(\%)\end{array}$ & $\begin{array}{c}\mathrm{Y} \\
\text { acumulado } \\
\text { (b) }\end{array}$ \\
\hline \multirow{8}{*}{ I } & \multirow{4}{*}{1} & 30 & 0,82 & 7,727 & 2,169 & 5,558 & 72 & 0,49 \\
\hline & & 20 & 1,14 & 10,714 & 3,854 & 6,860 & 64 & 0,43 \\
\hline & & 12 & 1,95 & 18,343 & 5,671 & 12,672 & 69 & 0,47 \\
\hline & & 8 & 3,25 & 28,864 & 9,266 & 19,598 & 68 & 0,46 \\
\hline & \multirow{4}{*}{2} & 30 & 1,63 & 14,892 & 5,040 & 9,852 & 66 & 0,45 \\
\hline & & 20 & 2,30 & 20,441 & 9,057 & 11,384 & 56 & 0,38 \\
\hline & & 12 & 3,92 & 35,971 & 13,634 & 22,337 & 62 & 0,42 \\
\hline & & 8 & 6,58 & 56,197 & 23,549 & 32,648 & 58 & 0,39 \\
\hline \multirow{10}{*}{ II } & \multirow{5}{*}{1} & 27 & 2,68 & 25,880 & 9,037 & 16,843 & 65 & 0,44 \\
\hline & & 20 & 3,38 & 31,128 & 12,266 & 18,862 & 61 & 0,41 \\
\hline & & 12 & 6,07 & 51,618 & 17,440 & 34,178 & 66 & 0,45 \\
\hline & & $12^{\mathrm{c}}$ & 5,86 & 50,489 & 21,023 & 29,466 & 58 & 0,39 \\
\hline & & $12^{\mathrm{d}}$ & 5,72 & 49,831 & 21,971 & 27,860 & 56 & 0,38 \\
\hline & \multirow{5}{*}{2} & 29 & 3,27 & 31,158 & 11,989 & 19,169 & 62 & 0,42 \\
\hline & & 20 & 4,25 & 38,848 & 15,037 & 23,811 & 61 & 0,41 \\
\hline & & 12 & 8,03 & 63,186 & 20,191 & 42,995 & 68 & 0,46 \\
\hline & & $12^{\mathrm{c}}$ & 7,66 & 68,576 & 27,914 & 40,662 & 59 & 0,40 \\
\hline & & $12^{\mathrm{d}}$ & 7,42 & 67,963 & 34,517 & 33,446 & 49 & 0,33 \\
\hline
\end{tabular}

(a) - kg DQO total $\left(\mathrm{m}^{3} \mathrm{~d}\right)^{-1}$

(b) - g SSV (g DQO total removida) ${ }^{-1}$

(c) e (d) - temperatura controlada a $25^{\circ} \mathrm{C}$ e $30{ }^{\circ} \mathrm{C}$, respectivamente.

Todas essas estimativas médias são bastante superiores às encontradas para o rendimento de lodo por FANG \& KWONG (1994), de 0,09 g SSV (g DQO total removida) ${ }^{-1}$ e KWONG \& FANG (1996), de $0,13 \mathrm{~g} \mathrm{SSV}$ (g DQO total removida) ${ }^{-1}$, as quais destacam a importância das características de biodegradabilidade dos SSTs do afluente na acumulação de lodo no reator UASB.

Também, observa-se grande diferença, comparando-se os valores apresentados na Tabela 5, com as estimativas de rendimento de lodo acumulado na manta (OLIVEIRA et al., 1997), cujos valores encontrados na fase I, para o reator 1 , variaram de 0,024 a 0,125 g SSV (g DQO total removida) ${ }^{-1} \mathrm{e}$, para o reator 2 , de 0,037 a 0,068 g SSV (g DQO total removida) ${ }^{-1}$. Na fase II, com operação à temperatura ambiente, para o reator 1 , variaram de 0,027 a $0,119 \mathrm{~g} \mathrm{SSV}$ (g DQO total removida) ${ }^{-1}$ e, para o reator 2 , de 0,023 a $0,119 \mathrm{~g} \mathrm{SSV}$ (g DQO total removida) ${ }^{-1}$; e com temperatura controlada a $25^{\circ}$ e $30^{\circ} \mathrm{C}$ variaram de 0,030 a $0,087 \mathrm{~g}$ SSV (g DQO total removida) ${ }^{-1}$, para TCOV média de 5,86 e 5,72 $\mathrm{kg}$ DQO total $\left(\mathrm{m}^{3} \mathrm{~d}\right)^{-1}$, e, para o reator 2, de 0,041 a 0,071 g SSV (g DQO total removida) ${ }^{-1}$, para TCOV média de 7,66 e 7,42 kg DQO total $\left(\mathrm{m}^{3} \mathrm{~d}\right)^{-1}$, respectivamente. Essa diferença pode ser atribuída, conforme já ressaltado, às perdas de metano com o efluente e para a atmosfera, acrescentando-se às perdas de lodo flotado no sedimentador e na câmara de gás e sedimentado na canaleta de saída do 
reator, as quais não estão incluídas nas estimativas de rendimento de lodo acumulado na manta e não foram sistematicamente analisadas durante o desenvolvimento do trabalho.

Entretanto, para ambas as estimativas relacionadas à acumulação de lodo na manta dos reatores, evidenciou-se o efeito do controle e o aumento da temperatura diminuindo os valores desses índices.

Em virtude de todos estes aspectos, a execução de um balanço de massa com boa confiabilidade nos parâmetros considerados fica prejudicada. Isto em consequiência da adoção de premissas que apresentam ressalvas, ou das dificuldades de obtenção de dados precisos para todos os parâmetros. Assim, a obtenção de conclusões definitivas sobre o destino das frações componentes das águas residuárias com altas concentrações de SST fica limitada.

Essa preocupação foi apresentada também por WANG (1994) em trabalho a respeito da hidrólise em reator UASB alimentado com esgoto doméstico bruto, destacando que suas estimativas de balanço de massa foram grosseiras, em conseqüência dos erros inevitáveis nas amostragens e, conseqüentemente, nos cálculos dos parâmetros. Primeiro porque toda a DQO do lodo do reator de hidrólise foi baseada na DQO dos SSs removidos. Em virtude da biodegradação e crescimento das bactérias, a composição dos SSs removidos pode variar. Em segundo lugar, os erros originados pelas amostragens de lodo para medidas dos perfis da manta e do lodo descartado dificilmente podem ser evitados. Também podem ocorrer outros erros em virtude das flutuações na composição da água residuária e da concentração do afluente e efluente. Desta forma, para obtenção de dados precisos para o balanço de massa, deve-se conduzir pesquisa detalhada utilizando água residuária sintética. A validade desta recomendação pode ser evidenciada nos trabalhos realizados por FANG \& KWONG (1994) e KWONG \& FANG (1996) utilizando água residuária contendo partículas de amido de milho, nos quais obtiveram estimativas de balanço de massa mais precisas.

As preocupações de WANG (1994) também podem ser estendidas para este trabalho. Contudo, os resultados obtidos foram bastante úteis para avaliações e comparações de desempenho de reatores UASB no tratamento das águas residuárias com altas concentrações de SST; nesse caso, particularmente, para aquelas provenientes de suinocultura. Isto da forma como foram apresentados e discutidos, porém sempre tendo em vista as ressalvas feitas anteriormente.

\section{CONCLUSÕES}

A partir do balanço de massa dos reatores UASB tratando águas residuárias de suinocultura com concentrações de SST ao redor de 500, 1.000, 1.500 e $2.000 \mathrm{mg} \mathrm{L}^{-1}$, operados com TCOV de 0,82 a $8,03 \mathrm{~kg}$ DQO total $\mathrm{m}^{-3} \mathrm{~d}^{-1}$, em condições de temperatura ambiente e controlada a $25^{\circ} \mathrm{C}$ e $30{ }^{\circ} \mathrm{C}$, podese concluir que:

- os reatores UASB foram eficientes na remoção da fração dissolvida e, principalmente, da fração devido à concentração de SST do afluente. Para TCOV em torno de $5 \mathrm{~kg}$ DQO total m${ }^{-3} \mathrm{~d}^{-1}$ (TCS em torno de $2 \mathrm{~kg} \mathrm{SSV} \mathrm{m}^{-3} \mathrm{~d}^{-1}$ ), nas condições de operação à temperatura ambiente, pôde-se obter eficiências de remoção de DQO total e de SST acima de 85\% e de DQO dissolvida acima de 75\%;

- a conversão da DQO em metano no reator UASB, independentemente da água residuária, pareceu estar associada à participação da DQO dissolvida na DQO total do afluente e às características de biodegradabilidade dos SSTs presentes no afluente. Para TDH e temperaturas mais altas, o desempenho é melhorado, independentemente do tipo de reator e da água residuária com altas concentrações de SST;

- para as águas residuárias de suinocultura, a conversão da DQO em metano pareceu ser influenciada pelo tipo de reator, com o reator UASB apresentando melhor desempenho, quando comparado com os resultados, apresentados na literatura, para o filtro anaeróbio, o reator anaeróbio de chicanas e o reator anaeróbio de filme fixo e leito expandido, operados em condições semelhantes; 
- a remoção física de sólidos do afluente foi um fenômeno importante na eficiência de remoção de DQO total, indicando que o descarte periódico do excesso de lodo acumulado na manta foi necessário e que a pré-solubilização dos sólidos num reator de hidrólise poderia melhorar o desempenho, no que diz respeito à produção de $\mathrm{CH}_{4}$, pois os resultados indicaram que a temperatura, a procedência dos sólidos e o tipo de reator podem afetar a conversão da DQO total em $\mathrm{CH}_{4}$.

\section{REFERÊNCIAS}

ASSOCIAÇÃO BRASILEIRA DE CRIADORES DE SUÍNOS. Rebanho suíno. Concórdia: Associação Brasileira de Criadores de Suínos, 1999. (Informe, 9)

APHA, AWWA, WPCF. Standard methods for the examination of water and wastewater. 15 th ed., Washington: American Public Health Association, 1985.

CHOU, C.Y.; HU, Y.Y.; HUANG, J.C. Automatic control for swine wastewater treatment systems. In: INTERNATIONAL SYMPOSIUM ON AGRICULTURAL AND FOOD PROCESSING WASTES, 7. 1995, Chicago. Proceedings... Chicago: ASAE, 1995. p.137-43.

CINTOLI, R.; Di SABATINO, B.; GALEOTTI, L.; BRUNO, G. Ammonium uptake by zeolite and treatment in UASB reactor of piggery wastewater. Water Science and Technology, Kidlington, v.32, n.12, p.73-81, 1995.

FANG, H.H.P.; KWONG, T.S. Degradation of starch particulates in a hybrid reactor. Water Science Technology, v.30, n.4, p.97-104, 1994.

FORESTI, E.; OLIVEIRA, R.A. de. Anaerobic treatment of piggery wasterwater in UASB reactors. In: INTERNATIONAL SYMPOSIUM ON AGRICULTURAL AND FOOD PROCESSING WASTES, 7., 1995, Chicago. Proceedings... Chicago: ASAE, 1995. p.309-18.

HASHEIDER, R.J.; SIEVERS, D. Limestone bed anaerobic filter for swine manure-Laboratory Study. Transactions of the ASAE, St. Joseph, v.27, n.3, p.834-9, 1984.

HOLMBERG, R.D.; HILL, D.T.; PRINCE, T.J.; VANDYKE, N.J. Potential of solid-liquid separation of swine wastes for methane production. Transactions of the ASAE, St. Joseph, v.26, n.6, p.1803-7, 1983.

KWONG, T.S.; FANG, H.H.P. Anaerobic degradation of cornstarch in wastewater in two upflow reactors. Journal of Environmental Engineering, New York, v.122, n.1, p.9-17, 1996.

LETTINGA, G.; VELSEN, A.F.M. van; HOBMA, S.W.; ZEEUW, W; KLAPWIJK, A. Use of the upflow sludge blanket (USB) reactor concept for biological wastewater treatment especially anaerobic treatment. Biotechnology and Bioengineering, New York, v.22, n.4, p.699-734, 1980.

LETTINGA, G. Sustainable integrated biological wastewater treatment. Water Science and Technology, Kidlington, v.33, n.3, p.85-98, 1996.

LETTINGA, G.; HULSHOFF-POL, L.W. UASB-process design for various types of wastewaters. Water Science and Technology, Kidlington, v.24, n.8, p.87-107, 1991.

NG, W.I.; CHIN, K.K. Treatment of piggerry wastewater by expanded -bed anaerobic filters. Biological Wastes, Barking, v.26, n.3, p.215-28, 1988.

OLIVEIRA, R.A. de; FORESTI E.; LUCAS JÚNIOR, J. Efeito da temperatura sobre o desempenho de reatores anaeróbios de fluxo ascendente com manta de lodo (UASB) tratando águas residuárias de suinocultura. In: CONGRESSO BRASILEIRO DE ENGENHARIA AGRÍCOLA, 25., 1996, Bauru. Anais... Bauru: Sociedade Brasileira de Engenharia Agrícola, 1996. 1 CD ROM. 
OLIVEIRA, R.A. de; VAZOLLER, R.F.; FORESTI, E. Sludge bed characteristics of UASB reactors: growth, activity, microbial structure and chemical composition of granules. In: INTERNATIONAL CONFERENCE ON ANAEROBIC DIGESTION, 8., 1997, Sendai, Japan. Proceedings... Sendai, Japan: IAWQ/JSWE, 1997. v.2, p.524-31.

SAYED, S.K.I. Anaerobic treatment of slaughterhouse wastewater using the UASB process. 1987.134 f. Tese (Ph.D) - Wageningen Agricultural University, The Netherlands, 1987.

SOUZA, M.E. Criteria for the utilization, design and operation of UASB reactors. Water Science Technology, Kidlington, v.18, n.12, p.55-69, 1986.

STRONACH, S.M.; RUDD, T.; LESTER, J.N. Anaerobic digestion process in industrial wastewater treatment. Berlin Heidelberg, Germany: Springer-Verlag, 1986.

VAN HAANDEL, A.C.; LETTINGA, G. Tratamento anaeróbio de esgotos: um manual para regiões de clima quente. Campina Grande: Epgraf, 1994.

WANG, K. Integrated anaerobic and aerobic treatment of sewage. 1994. 145 f. Tese (Ph.D) Wageningen Agricultural University, The Netherlands, 1994.

YANG, P.Y., CHOU, C.Y. Horizontal-baffled anaerobic reactor treating diluted swine wastewater. Agricultural Wastes, Barking, v.14, p.221-39, 1985.

ZHANG, R.H.; DAGUE, R.R. Treatment of swine wastes by the anaerobic sequencing batch reactors system. In: INTERNATIONAL SYMPOSIUM ON AGRICULTURAL AND FOOD PROCESSING WASTES, 7., 1995, Chicago. Proceedings... Chicago: ASAE, 1995. p.301-8. 